\title{
Very early recurrence predicts long-term outcome in patients after atrial fibrillation catheter ablation: a prospective study
}

\author{
Yangjing Xue ${ }^{1 \dagger}$, Xiaoning Wang ${ }^{3 \dagger}$, Saroj Thapa', Luping Wang ${ }^{4}$, Jiaoni Wang ${ }^{1}$, Zhiqiang Xu', Shaoze Wu',
} Luyuan Tao ${ }^{1}$, Guoqiang Wang ${ }^{1}$, Lu Qian', Lianming Liao ${ }^{5}$, Baohua Liu²* and Kangting Ji ${ }^{2^{*}}$

\begin{abstract}
Background: Long-term recurrence $(L R)$ is a tendency that re-occurs within 3 months after catheter ablation for atrial fibrillation (AF). Whether very early recurrence (VER) within 7 days of post ablation is a prognostic factor of LR or not is unclear. For this reason, present study sought to examine the relationship between VER and LR.
\end{abstract}

Methods: In this prospective analysis 378 consecutive patients underwent an initial catheter ablation for paroxysmal or persistent AF. The association between VER and LR was analyzed by univariate and multivariate Cox regression, as well as time-dependent receiver operator characteristic (ROC) analysis.

Results: After a mean follow-up of $14.71 \pm 8.58$ months, 81 (65.90\%) patients with VER experienced LR and were associated with lower event of free survival from LR (Log rank test, $P<0.001$ ). Multivariate Cox regression analysis revealed that VER $(H R=7.02,95 \% \mathrm{Cl}=4.78-10.31 ; P<0.001)$, left atrial enlargement $(\mathrm{HR}=2.92,95 \% \mathrm{Cl}=1.88-4.54$; $P<0.001)$, tendency in advanced age $(H R=1.50,95 \% \mathrm{Cl}=0.99-2.28 ; P=0.054)$, and tendency in male $(\mathrm{HR}=0.71$, $95 \% \mathrm{Cl}=0.50-1.01 ; P=0.060$ ) were independent predictors of LR. According to time-dependent ROC analysis, it was found that VER was more sensitive than common risk factors in predicting LR $(0.74$ vs $0.66, P<0.001)$ and combination model further improved the $C$ statistic for predicting LR ( 0.82 vs $0.66, P<0.001)$.

Conclusions: After a single procedure of catheter ablation, patients with VER were strongly associated with LR and combination of VER and common risk factors could further improve prediction of patients who were at high risk for LR.

Keywords: Atrial fibrillation, Catheter ablation, Very early recurrence, Long-term recurrence

\section{Background}

Catheter ablation is the mainstay therapy for atrial fibrillation (AF), but the high rate of long-term recurrence (LR) is a limitation of the procedure. Nonparoxysmal AF, sleep apnea, obesity, left atrial enlargement, advanced age, hypertension, left atrial fibrosis and recurrence of AF within the first 3 months after catheter ablation have been identified to be the

\footnotetext{
* Correspondence: bhbh3699999@163.com; jikt@wzmc.edu.cn

${ }^{\dagger}$ Equal contributors

${ }^{2}$ Department of Rehabilitation, the Second Affiliated Hospital and Yuying Children's Hospital of Wenzhou Medical University, Xueyuanxi Road, No 109, Wenzhou, Zhejiang 325000, China

'Department of Cardiology, the Second Affiliated Hospital and Yuying Children's Hospital of Wenzhou Medical University, Xueyuanxi Road, No 109, Wenzhou, Zhejiang 325000, China

Full list of author information is available at the end of the article
}

LR predictors [1-14]. Among them, recurrence of AF within the first 3 months is considered to be the most important predictor of long-term treatment failure [5-14]. Based on these studies, a so-called blanking period, the duration ranging from the first 7 days to 3 months post ablation, is proposed [5-15].

In the clinical practice, it has been found that lots of patients had episodes of AF as early as 7 days of post ablation. In the present study, it was aimed to examine the relationship of recurrence within 7 days, which we defined as very early recurrence (VER), and LR after 3 months. We hypothesized that VER was a prognostic factor of LR after 3 months. 


\section{Methods}

This prospective study included 378 consecutive patients with paroxysmal $(n=168)$ or persistent $(n=210)$ AF who underwent an initial ablation at the Second Affiliated hospital and Yuying Children's Hospital of Wenzhou Medical University, from January 2013 and December 2014.
Paroxysmal AF is defined as AF that terminates spontaneously or under anti-arrhythmic drugs (AADs) within 7 days of onset. Persistent AF is defined as continuous AF sustaining for more than 7 days. Patients were excluded if they aged $<20$, had pregnancy, prior cardiac surgery, implanted pacemaker, chronic renal

Table 1 Baseline characteristics of the Patients ${ }^{\mathrm{a}}$

\begin{tabular}{|c|c|c|c|c|}
\hline \multirow[t]{2}{*}{ Variables } & \multirow{2}{*}{$\begin{array}{l}\text { Total } \\
N=378\end{array}$} & \multicolumn{2}{|c|}{ Long-term recurrence } & \multirow[t]{2}{*}{$P$-value } \\
\hline & & $\begin{array}{l}\text { Without } \\
N=255\end{array}$ & $\begin{array}{l}\text { With } \\
N=123\end{array}$ & \\
\hline Age, years & $65.37 \pm 10.44$ & $63.69 \pm 10.40$ & $68.85 \pm 9.68$ & $<0.001$ \\
\hline Age $\geq 65$ years, $\mathrm{n}(\%)$ & $222(58.70 \%)$ & 131 (51.40\%) & $91(74.00 \%)$ & $<0.001$ \\
\hline Male, n (\%) & 215 (56.90\%) & $156(61.20 \%)$ & $59(48.00 \%)$ & 0.015 \\
\hline $\mathrm{BMI}, \mathrm{kg} / \mathrm{m}^{2}$ & $24.43 \pm 3.08$ & $24.07 \pm 3.00$ & $25.17 \pm 3.15$ & 0.001 \\
\hline \multicolumn{5}{|l|}{ Type of AF } \\
\hline Paroxysmal, n (\%) & $168(44.40 \%)$ & $128(50.20 \%)$ & $40(32.50 \%)$ & 0.001 \\
\hline Persistent, n (\%) & $210(55.60 \%)$ & $127(49.80 \%)$ & $87(67.50 \%)$ & 0.001 \\
\hline Duration of AF, months & $32.11 \pm 44.82$ & $33.44 \pm 48.54$ & $29.37 \pm 35.91$ & 0.409 \\
\hline Hypertension, n (\%) & $223(59.00 \%)$ & $141(55.30 \%)$ & $82(66.70 \%)$ & 0.035 \\
\hline Systolic BP, mmHg & $135.17 \pm 20.83$ & $134.39 \pm 21.27$ & $136.80 \pm 19.88$ & 0.291 \\
\hline Diastolic BP, mmHg & $82.94 \pm 51.28$ & $81.76 \pm 42.34$ & $85.39 \pm 66.21$ & 0.520 \\
\hline Diabetes, n (\%) & $56(14.80 \%)$ & $30(11.80 \%)$ & $26(21.10 \%)$ & 0.016 \\
\hline $\mathrm{FBG}, \mathrm{mmol} / \mathrm{L}$ & $5.14 \pm 1.15$ & $5.09 \pm 1.02$ & $5.26 \pm 1.39$ & 0.117 \\
\hline History of HF, n (\%) & $46(12.20 \%)$ & $20(7.80 \%)$ & $26(21.10 \%)$ & $<0.001$ \\
\hline Left ventricular EF, \% & $63.48 \pm 7.52$ & $63.82 \pm 7.35$ & $62.78 \pm 7.85$ & 0.211 \\
\hline Left atrial dimension, $\mathrm{mm}$ & $40.82 \pm 6.41$ & $39.50 \pm 5.72$ & $43.56 \pm 6.91$ & $<0.001$ \\
\hline Left atrial $\geq 50$ mm, n (\%) & $39(10.30 \%)$ & $13(5.10 \%)$ & $26(21.10 \%)$ & $<0.001$ \\
\hline Moderate valvular heart disease, n (\%) & $6(1.60 \%)$ & $3(1.20 \%)$ & $3(2.40 \%)$ & 0.357 \\
\hline CAD, n (\%) & $26(6.90 \%)$ & $12(4.70 \%)$ & $14(11.40 \%)$ & 0.016 \\
\hline Prior Stroke/TIA, n (\%) & $49(13.00 \%)$ & $31(12.20 \%)$ & $18(14.60 \%)$ & 0.502 \\
\hline CHADS2 Score & $1.34 \pm 1.19$ & $1.17 \pm 1.10$ & $1.71 \pm 1.30$ & $<0.001$ \\
\hline CHA2DS2-VASC Score & $2.81 \pm 1.81$ & $2.49 \pm 1.70$ & $3.48 \pm 1.83$ & $<0.001$ \\
\hline HAS-BLED Score & $2.47 \pm 1.06$ & $2.32 \pm 1.02$ & $2.79 \pm 1.07$ & $<0.001$ \\
\hline CRP within $24 \mathrm{~h}$ post-procedure, mg/dL & $6.36 \pm 10.27$ & $6.38 \pm 10.87$ & $6.32 \pm 8.94$ & 0.954 \\
\hline \multicolumn{5}{|l|}{ Medication at hospital discharge } \\
\hline \multicolumn{5}{|l|}{ Oral anticoagulant } \\
\hline Warfarin, n (\%) & 297 (78.57\%) & $194(76.10 \%)$ & $103(83.70 \%)$ & 0.089 \\
\hline Dabigatran, n (\%) & $73(19.31 \%)$ & $54(21.20 \%)$ & $19(15.40 \%)$ & 0.186 \\
\hline Xa inhibitor, n (\%) & $8(2.12 \%)$ & $7(2.70 \%)$ & $1(0.80 \%)$ & 0.221 \\
\hline Statins, n (\%) & $269(71.20 \%)$ & $174(68.20 \%)$ & $95(77.20 \%)$ & 0.070 \\
\hline ACEI/ARB, n (\%) & $169(44.70 \%)$ & $103(40.40 \%)$ & $66(53.70 \%)$ & 0.015 \\
\hline Beta-blockers, n (\%) & $111(29.40 \%)$ & $70(27.50 \%)$ & $41(33.30 \%)$ & 0.239 \\
\hline Vaughan Williams class I or III AAD, n (\%) & $342(90.50 \%)$ & 235 (92.20\%) & 107 (87.00\%) & 0.109 \\
\hline Amiodarone, n (\%) & $328(86.80 \%)$ & $228(89.40 \%)$ & $100(81.30 \%)$ & 0.029 \\
\hline Propafenon, n (\%) & $14(3.70 \%)$ & $7(2.70 \%)$ & $7(5.70 \%)$ & 0.155 \\
\hline
\end{tabular}

$B M I$ body mass index, $A F$ atrial fibrillation, $F B G$ fasting blood glucose, $H F$ heart failure, $E F$ ejection fraction, $C A D$ coronary artery disease, $T I A$ transient ischemic attack, $C R P$ C-reactive protein, $A A D$ anti-arrhythmia drug

a Plus-minus values are means \pm SD. Percentages do not sum to 100 because of rounding 
failure requiring hemodialysis, and severe mitral valve disease. All patients gave written informed consent and the study protocol was approved by our institutional review board.

For every patient, step-wise ablation strategy was performed, including circumferential pulmonary vein isolation (PVI), complex fractionated atrial electrograms, and linear ablation. The electrophysiological evaluation of PVI was bi-directional conduction block between left atria (LA) and pulmonary veins (PVs). Whether to perform additional ablation including tricuspid valve isthmus ablation, continuous fractionated atrial electrogram ablation, and LA linear ablation was decided by the operator and/or the attending physician. The ablation procedure followed the method described by Liu X et al. $[16,17]$.

After the ablation procedure, patients remained hospitalized under continuous electrocardiography monitoring for at least 7 days. Patients received $24 \mathrm{~h}$ Holter monitoring at 3, 6 and 12 months follow-ups after procedure and every 12 months thereafter. Among follow-ups, all patients were encouraged to visit doctors for ECGs or Holter monitoring for any symptoms suggestive of AT onset.

AADs continued for 1-3 months after the ablation procedure. LR was defined as any asymptomatic or symptomatic atrial tachyarrhythmia (AT) lasting $>30$ s off AADs after the initial 3-month blanking period. VER was defined as sustained AT (lasting $>30 \mathrm{~s}$ ) on or off AADs recurred within 7 days post ablation.

\section{Statistical analysis}

Depending on the distribution, the continuous data were presented as median (25th-75th percentiles) or as mean \pm SD. Categorical data were presented as counts or proportions. The differences between groups were assessed with the $\chi^{2}$ test or Fisher's exact test for categorical data and the nonparametric Wilcoxon rank-sum test or Student test for continuous data.

Factors associated with recurrence arrhythmia during follow-ups were assessed in univariate and multivariable Cox proportional hazard models. Factors with $P$ values $<0.1$ in univariate analyses were included in stepwise multivariate Cox regression models. Time-dependent receiver operator characteristic (ROC) curve analysis was generated to test the predictive discrimination of patients with or without LR. A two-tailed value of $P<0.05$ was considered to indicate the statistical significance.

\section{Results}

Baseline characteristics of patients are summarized in Table 1. AF was paroxysmal in 168 (44.44\%) patients and persistent in 210 (55.56\%). Only 6 patients had moderate valvular heart disease. Risk of thromboembolic (CHADS2 and CHADS-VASc Score) and bleeding (HAS-BLED Score) complications were both significantly high in patients with LR. Warfarin usage at hospital discharge tended to be more frequent in patients with $\operatorname{LR}(P=0.089)$. Advanced age (age $\geq 65$ years), female gender, increased BMI, persistent AF, hypertension, diabetes, history of heart failure (HF), decreased left ventricular ejection fraction $(E F)$, left atrial enlargement (left atrial $\geq 50 \mathrm{~mm}$ ), statins usage, and ACEI/ARB usage were significantly more frequent in patients with LR.

After a single ablation procedure, 112 patients (29.63\%) experienced VER within the first 7 days post ablation while LR cumulatively occurred in 123 (32.54\%) patients after the initial 3-month blanking period.

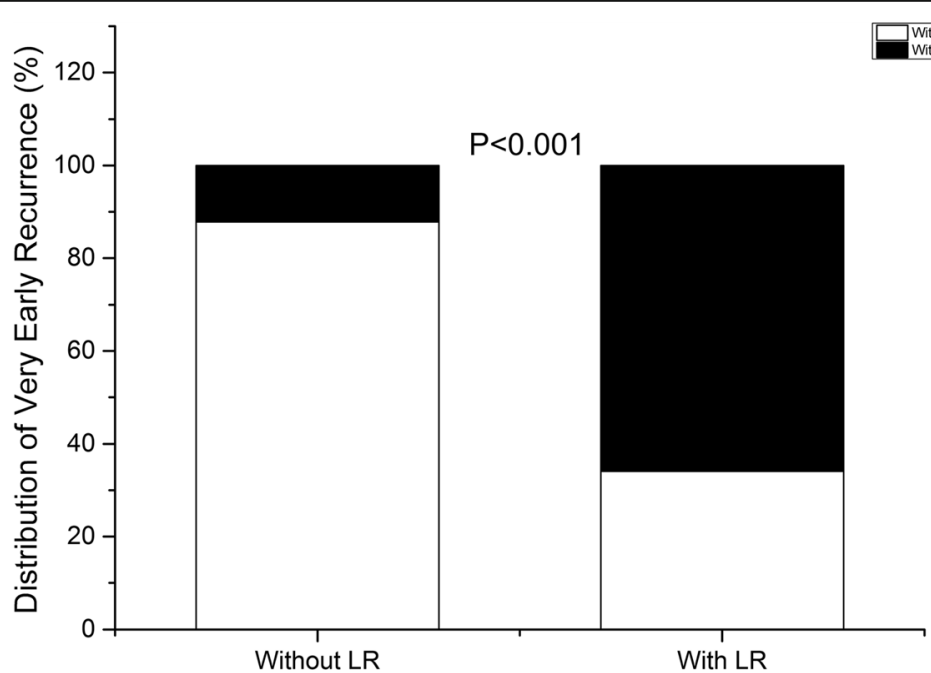

Fig. 1 Relationship between very early recurrence (VER) and long-term recurrence (LR). In patients without LR, the constitution of VER was of 12.20\%; In patients with $L R$, the constitution of VER was of $65.90 \%$ 


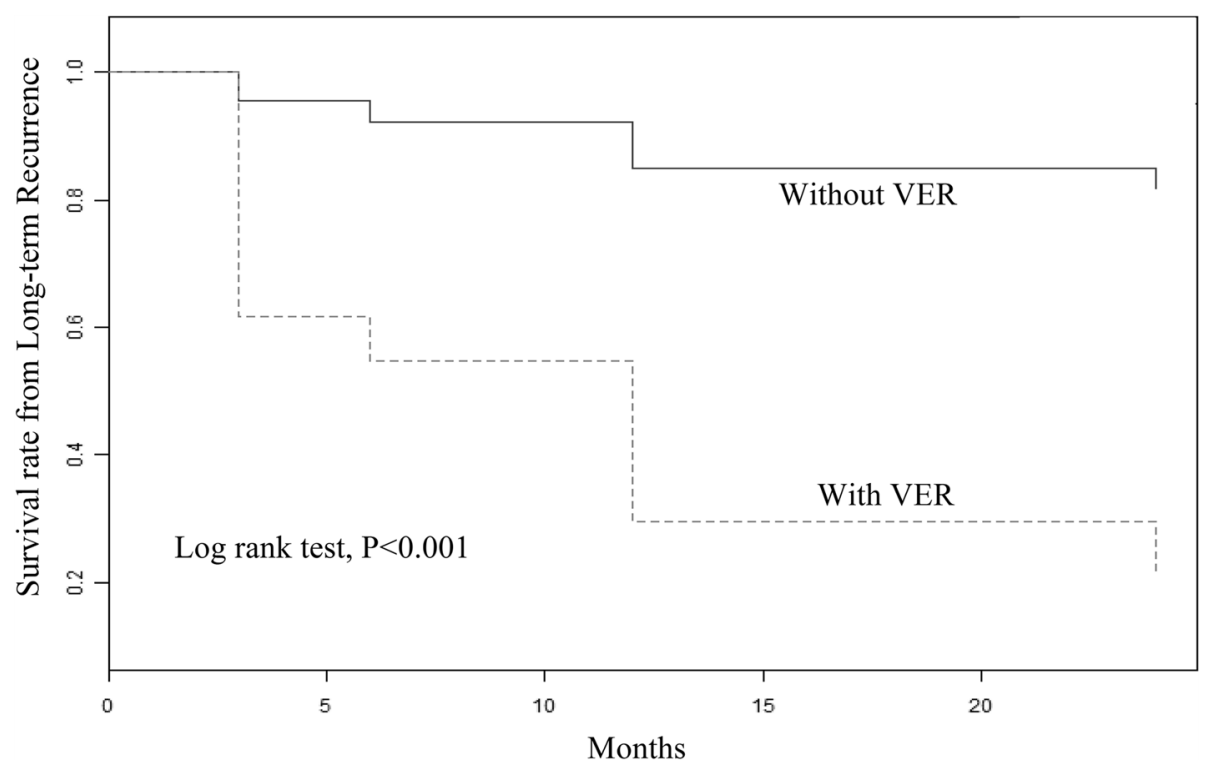

Fig. 2 Event-free survival from the long-term recurrence (LR) for patients with and without very early recurrence (VER)

Among these 112 patients with VER, 81 (65.90\%) patients experienced LR (Fig. 1).

Figure 2 shows the event-free survival from the LR for patients with and without VER within 7 days. After a mean follow-up of $14.71 \pm 8.58$ months, patients with VER were associated with LR (Log rank test, $P<0.001)$.

Univariate Cox analysis was performed and identified that VER was associated with LR $(P<0.10)$, and similarly to the factors including advanced age (age $\geq 65$ years), $\mathrm{BMI}$, persistent $\mathrm{AF}$, duration of $\mathrm{AF}$, hypertension, diabetes, history of heart failure, left ventricular EF, left atrial enlargement, ACEI/ARB usage. In multivariable Cox regression analysis, independent predictors of LR in this study were VER $(H R=7.02,95 \% \mathrm{CI}=4.78-10.31 ; P<0.001)$, left atrial enlargement $(\mathrm{HR}=2.92,95 \% \mathrm{CI}=1.88-4.54 ; P<0.001)$, tendency in advanced age (age $\geq 65$ years) $(\mathrm{HR}=1.50$, 95\% CI $=0.99-2.28 ; P=0.054)$, and tendency in male $(\mathrm{HR}=0.71,95 \% \mathrm{CI}=0.50-1.01 ; P=0.060)($ Table 2$)$.

To further assess the potential prognostic value of VER in predicting cumulative LR, we performed timedependent ROC analysis. C statistic for VER was significantly greater than model based on established common risk factors (left atrial enlargement, age $\geq 65$, male) in

Table 2 The results of the multivariable Cox regression analysis of the independent correlates for the LR

\begin{tabular}{lllll}
\hline Parameters & OR & $95 \%$ Cl Low & $95 \%$ Cl Upp & $P$-value \\
\hline VER & 7.02 & 4.78 & 10.31 & $<0.001$ \\
Left atrial enlargement & 2.92 & 1.88 & 4.54 & $<0.001$ \\
Advanced age & 1.50 & 0.99 & 2.28 & 0.054 \\
Male & 0.71 & 0.50 & 1.01 & 0.060 \\
\hline
\end{tabular}

LR Long-term recurrence, VER Very Early Recurrence this study ( 0.74 vs $0.66, P<0.001)$ (Fig. 3$)$. When VER was combined with the established common risk factors, VER improved the $C$ statistic $(0.82$ vs $0.66, P<0.001)$, indicating that the combination of VER with common risk factors has a greater potential to predict LR (Fig. 4).

\section{Discussion}

The major findings of this study are as follows; after a single procedure of catheter ablation for paroxysmal or

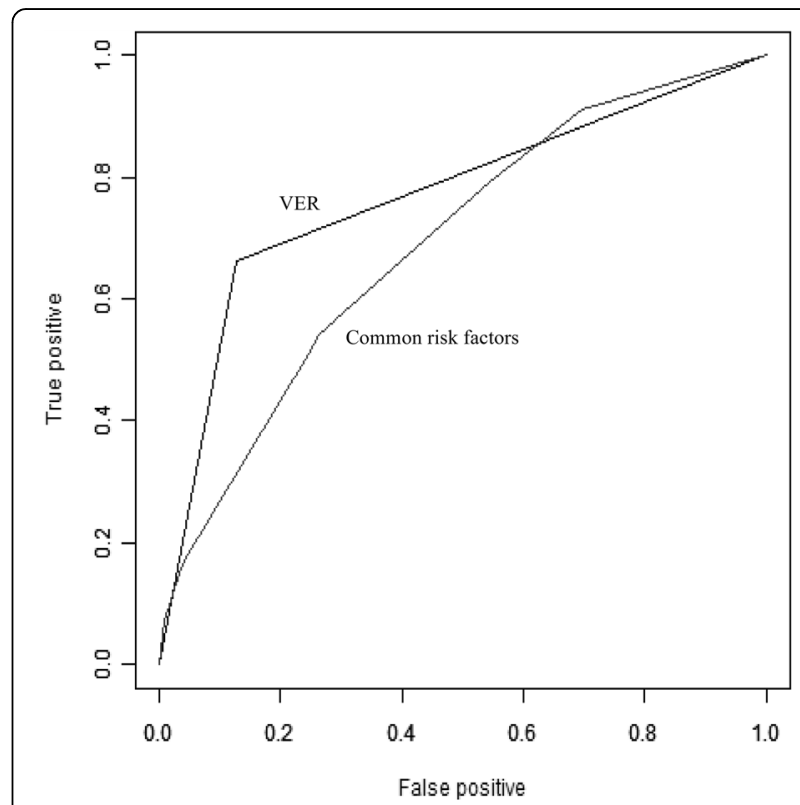

Fig. 3 Time-dependent ROC analysis based on very early recurrence (VER) and established common risk factors (0.74 vs 0.66 , $P<0.001)$, respectively 


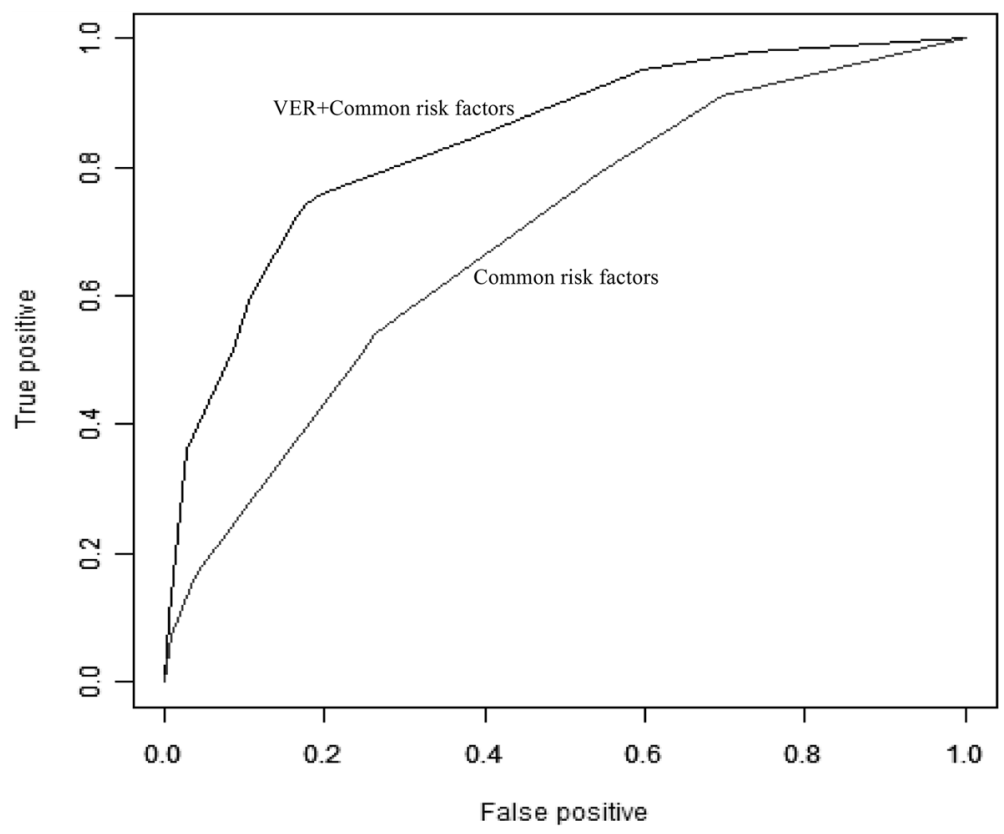

Fig. 4 Time-dependent ROC analysis based on combined model and established common risk factors $(0.82$ vs $0.66, P<0.001)$

persistent AF, (1) Above half of patients with VER (65.90\%) experienced subsequent LR and were associated with lower event-free survival from LR, (2) VER was an independent predictor of LR after adjustment for common risk factors of AF, (3) VER was more sensitive than common risk factors in predicting LR and combination model was superior in predicting LR.

The purpose of catheter ablation is to eliminate underlying cardiac arrhythmia by destroying myocardial tissue through energy. However, due to the complexity of the underlying pathological mechanisms, AF recurs frequently after an initially successful ablation procedure. Reported frequency of LR ranges from 5 to $63 \%$, depending on method and intensity of surveillance, technique used, patient characteristics, and definition of success, with a mean overall successful rate of approximately $70 \%$ [18]. In the present study, we found the cumulative LR was about $32.54 \%$ at a mean follow-up of $14.71 \pm 8.58$ months after a single procedure. Among most patients, AF recurred within 7 days.

Recurrence within 3 months following catheter ablation is relatively common regardless of catheter techniques used and is a predictor of LR [5-14]. However, definitions of recurrence time point within the blanking period vary in the reported studies. Arya et al. [9] defined early recurrence as a sustained episode of AF within 7 days immediately after the procedure, while others defined it by a sustained episode of AF within 2 weeks, [5] 1 month, [6, 7] 6 weeks, [8, 10] and 3 months [11-14] during the blanking period. The optimal time to define early recurrence remains to be determined. In this study, we defined sustained AT episode within 7 days as VER since 112 patients (29.63\%) experienced it. By using multivariate Cox analysis, VER independently predicted subsequent LR. Mechanisms of arrhythmia recurrence within 3 months of post ablation remain to be fully elucidated and may include reconnection of the PVs, [19] inflammatory response to thermal injury and/or pericarditis, $[20,21]$ imbalance of the autonomic nervous system, [22, 23] and a delayed effect of AF ablation [23, 24].

The use of 3-month blanking period has been proposed on the assumption that early recurrence will lead to delayed cure and should not prompt immediate re-ablation attempts [15, 25-27]. However, patients with early recurrence and delayed cure were of varied proportion [25-27] and the mechanisms and significance of early arrhythmia remains unclear [19-24]. Given the fact that early recurrence is a strong prognostic factor of LR, delayed re-intervention of tachyarrhythmia within blanking period may be a cause of failure to prevent LR. Indeed, Lellouche et al. [7] evaluated the use of early re-ablation on long-term outcome among patients with early recurrence. After a mean follow-up of $11 \pm 11$ months, patients with early re-ablation had a lower rate of clinical recurrences. Thus, detection of patients who are at high risk for LR and strategies of aggressive re-intervention may improve at long-term outcome. In our study, VER was more sensitive than common risk factors in prediction of LR. Moreover, when combining VER with common risk factors, it could further improve prediction of LR. 
It must be noted that there are limitations in our study. Above all, it is a prospective cohort study and should be validated in large randomized controlled studies. Furthermore, monitoring of atrial tachyarrhythmia recurrence was based on the review of 12-lead electrocardiograms and Holter recordings at follow-up visits. It is likely that more invasive and detailed monitoring of atrial tachyarrhythmia should be offered. Finally, the precise mechanisms of VER and strategies to prevent VER were not investigated and required further research.

\section{Conclusions}

To sum up, the results of this study confirm that VER is observed frequently after a single procedure of catheter ablation and it was strongly associated with LR. Combination between VER and common risk factors could further improve prediction of patients who were at high risk for LR. Whether more aggressively invasive examinations and interventions are helpful for these patients, deserve further studies.

\section{Abbreviations}

AADs: Anti-arrhythmic drugs; AF: Atrial fibrillation; AT: Atrial tachyarrhythmia; LA: Left atria; LR: Long-term recurrence; PVI: Pulmonary vein isolation; PVs: Pulmonary veins; ROC: Receiver operator characteristic; VER: Very early recurrence

\section{Acknowledgements}

Not Applicable.

\section{Funding}

Not applicable.

\section{Availability of data and materials}

The datasets used and/or analysed during the current study available from the corresponding author on reasonable request.

\section{Authors' contributions}

KTJ and BHL analyzed and interpreted the patient data. YJX and XNW both were major contributors in writing the manuscript. YJX, XNW, ST, LPW, JNW, ZQX, SZW, LYT, GQW, LQ participated in data acquisition. YJX and LML performed statistical analysis. All authors read and approved the final manuscript.

\section{Competing interests}

The authors declare that they have no competing interests.

\section{Consent for publication}

Not applicable.

\section{Ethics approval and consent to participate}

The study was approved by the institutional review board of the Second Affiliated hospital and Yuying Children's Hospital of Wenzhou Medical University, and all patients provided written informed consent.

\section{Publisher's Note}

Springer Nature remains neutral with regard to jurisdictional claims in published maps and institutional affiliations.

\section{Author details}

'Department of Cardiology, the Second Affiliated Hospital and Yuying Children's Hospital of Wenzhou Medical University, Xueyuanxi Road, No 109, Wenzhou, Zhejiang 325000, China. ${ }^{2}$ Department of Rehabilitation, the Second Affiliated Hospital and Yuying Children's Hospital of Wenzhou
Medical University, Xueyuanxi Road, No 109, Wenzhou, Zhejiang 325000, China. ${ }^{3}$ Department of Intensive Care Unit, Zhengzhou Central Hospital Affiliated to Zhengzhou University, Tongbaibei Road, No 195, Zhengzhou, Henan 450000, China. ${ }^{4}$ Department of Endocrinology, the Fourth Affiliated Hospital, Zhejiang University School of Medicine, Shangcheng Road, No N1, Yiwu, Zhejiang 322000, China. ${ }^{5}$ Department of Oncology, Academy of Integrative Medicine, Fujian University of Traditional Chinese Medicine, Huatuo Road, No 1, Fuzhou, Fujian 350122, China.

Received: 16 October 2016 Accepted: 6 April 2017

Published online: 08 May 2017

\section{References}

1. Ouyang F, Tilz R, Chun J, Schmidt B, Wissner E, Zerm T, Neven K, Kokturk B, Konstantinidou M, Metzner $\mathrm{A}$, et al. Long-term results of catheter ablation in paroxysmal atrial fibrillation: lessons from a 5-year follow-up. Circulation. 2010;122(23):2368-77.

2. Tzou WS, Marchlinski FE, Zado ES, Lin D, Dixit S, Callans DJ, Cooper JM, Bala R, Garcia F, Hutchinson MD, et al. Long-term outcome after successful catheter ablation of atrial fibrillation. Circ Arrhythm Electrophysiol. 2010;3(3):237-42.

3. Weerasooriya R, Khairy P, Litalien J, Macle L, Hocini M, Sacher F, Lellouche N, Knecht S, Wright M, Nault I, et al. Catheter ablation for atrial fibrillation: are results maintained at 5 years of follow-up? J Am Coll Cardiol. 2011;57(2): 160-6.

4. Scherr D, Khairy P, Miyazaki S, Aurillac-Lavignolle V, Pascale P, Wilton SB, Ramoul K, Komatsu Y, Roten $L$, Jadidi A, et al. Five-year outcome of catheter ablation of persistent atrial fibrillation using termination of atrial fibrillation as a procedural endpoint. Circ Arrhythm Electrophysiol. 2015;8(1):18-24.

5. Oral H, Knight BP, Ozaydin M, Tada H, Chugh A, Hassan S, Scharf C, Lai SW, Greenstein R, Pelosi Jr F, et al. Clinical significance of early recurrences of atrial fibrillation after pulmonary vein isolation. J Am Coll Cardiol. 2002;40(1): $100-4$.

6. Lee SH, Tai CT, Hsieh MH, Tsai CF, Lin YK, Tsao HM, Yu WC, Huang JL, Ueng $\mathrm{KC}$, Cheng JJ, et al. Predictors of early and late recurrence of atrial fibrillation after catheter ablation of paroxysmal atrial fibrillation. J Interv Card Electrophysiol. 2004;10(3):221-6.

7. Lellouche N, Jais P, Nault I, Wright M, Bevilacqua M, Knecht S, Matsuo S, Lim KT, Sacher F, Deplagne A, et al. Early recurrences after atrial fibrillation ablation: prognostic value and effect of early reablation. J Cardiovasc Electrophysiol. 2008;19(6):599-605.

8. Roux JF, Zado E, Callans DJ, Garcia F, Lin D, Marchlinski FE, Bala R, Dixit S, Riley M, Russo AM, et al. Antiarrhythmics after ablation of Atrial fibrillation (5A study). Circulation. 2009;120(12):1036-40.

9. Arya A, Hindricks G, Sommer P, Huo Y, Bollmann A, Gaspar T, Bode K, Husser $\mathrm{D}$, Kottkamp H, Piorkowski C. Long-term results and the predictors of outcome of catheter ablation of atrial fibrillation using steerable sheath catheter navigation after single procedure in 674 patients. Europace. 2010; 12(2):173-80.

10. Leong-Sit P, Roux JF, Zado E, Callans DJ, Garcia F, Lin D, Marchlinski FE, Bala R, Dixit S, Riley M, et al. Antiarrhythmics after ablation of atrial fibrillation (5A study): six-month follow-up study. Circ Arrhythm Electrophysiol. 2011;4(1):11-4.

11. Pokushalov E, Romanov A, Corbucci G, Bairamova S, Losik D, Turov A, Shirokova N, Karaskov A, Mittal S, Steinberg JS. Does atrial fibrillation burden measured by continuous monitoring during the blanking period predict the response to ablation at 12-month follow-up? Heart Rhythm. 2012;9(9):1375-9.

12. Kaitani K, Inoue K, Kobori A, Nakazawa Y, Ozawa T, Kurotobi T, Morishima I, Miura F, Watanabe T, Masuda M, et al. Efficacy of Antiarrhythmic drugs short-term use after catheter ablation for Atrial fibrillation (EAST-AF) trial. Eur Heart J. 2016;37(7):610-8.

13. Themistoclakis S, Schweikert RA, Saliba WI, Bonso A, Rossillo A, Bader G, Wazni O, Burkhardt DJ, Raviele A, Natale A. Clinical predictors and relationship between early and late atrial tachyarrhythmias after pulmonary vein antrum isolation. Heart Rhythm. 2008;5(5):679-85.

14. Koyama T, Sekiguchi $Y$, Tada H, Arimoto T, Yamasaki H, Kuroki K, Machino T, Tajiri K, Zhu XD, Kanemoto M, et al. Comparison of characteristics and significance of immediate versus early versus no recurrence of atrial fibrillation after catheter ablation. Am J Cardiol. 2009;103(9):1249-54

15. Calkins H, Kuck KH, Cappato R, Brugada J, Camm AJ, Chen SA, Crijns HJ, Damiano Jr RJ, Davies DW, Di Marco J, et al. 2012 HRS/EHRA/ECAS expert consensus statement on catheter and surgical ablation of atrial fibrillation: recommendations for patient selection, procedural techniques, patient 
management and follow-up, definitions, endpoints, and research trial design: a report of the Heart Rhythm Society (HRS) task force on catheter and surgical ablation of Atrial fibrillation. Developed in partnership with the European heart rhythm association (EHRA), a registered branch of the European Society of Cardiology (ESC) and the European cardiac arrhythmia Society (ECAS); and in collaboration with the American College of Cardiology (ACC), American Heart Association (AHA), the Asia Pacific Heart Rhythm Society (APHRS), and the Society of Thoracic Surgeons (STS). Endorsed by the governing bodies of the American College of Cardiology Foundation, the American Heart Association, the European cardiac arrhythmia Society, the European heart rhythm association, the Society of Thoracic Surgeons, the Asia Pacific Heart Rhythm Society, and the Heart Rhythm Society. Heart Rhythm. 2012;9(4):632-696 e621.

16. Liu X, Tan HW, Wang XH, Shi HF, Li YZ, Li F, Zhou L, Gu JN. Efficacy of catheter ablation and surgical CryoMaze procedure in patients with long-lasting persistent atrial fibrillation and rheumatic heart disease: a randomized trial. Eur Heart J. 2010;31(21):2633-41.

17. Zhang XD, Gu J, Jiang WF, Zhao L, Zhou L, Wang YL, Liu YG, Liu X. Optimal rhythm-control strategy for recurrent atrial tachycardia after catheter ablation of persistent atrial fibrillation: a randomized clinical trial. Eur Heart J. 2014;35(20):1327-34.

18. Marine JE. Catheter ablation therapy for supraventricular arrhythmias. JAMA. 2007;298(23):2768-78.

19. Lubitz SA, Fischer A, Fuster V. Catheter ablation for atrial fibrillation. BMJ. 2008;336(7648):819-26.

20. Grubman E, Pavri BB, Lyle S, Reynolds C, Denofrio D, Kocovic DZ. Histopathologic effects of radiofrequency catheter ablation in previously infarcted human myocardium. J Cardiovasc Electrophysiol. 1999;10(3):336-42.

21. Tanno K, Kobayashi Y, Kurano K, Kikushima S, Yazawa T, Baba T, Inoue S, Mukai H, Katagiri T. Histopathology of canine hearts subjected to catheter ablation using radiofrequency energy. Jpn Circ J. 1994;58(2):123-35.

22. Pappone C, Santinelli V, Manguso F, Vicedomini G, Gugliotta F, Augello G, Mazzone P, Tortoriello V, Landoni G, Zangrillo A, et al. Pulmonary vein denervation enhances long-term benefit after circumferential ablation for paroxysmal atrial fibrillation. Circulation. 2004;109(3):327-34.

23. Hsieh MH, Chiou CW, Wen ZC, Wu CH, Tai CT, Tsai CF, Ding YA, Chang MS, Chen SA. Alterations of heart rate variability after radiofrequency catheter ablation of focal atrial fibrillation originating from pulmonary veins. Circulation. 1999;100(22):2237-43.

24. Langberg JJ, Borganelli SM, Kalbfleisch SJ, Strickberger SA, Calkins H, Morady F. Delayed effects of radiofrequency energy on accessory atrioventricular connections. Pacing Clin Electrophysiol. 1993;16(5 Pt 1):1001-5.

25. O'Donnell D, Furniss SS, Dunuwille A, Bourke JP. Delayed cure despite early recurrence after pulmonary vein isolation for atrial fibrillation. Am J Cardiol. 2003;91(1):83-5.

26. Bertaglia E, Stabile G, Senatore G, Zoppo F, Turco P, Amellone C, De Simone A, Fazzari M, Pascotto P. Predictive value of early atrial tachyarrhythmias recurrence after circumferential anatomical pulmonary vein ablation. Pacing Clin Electrophysiol. 2005;28(5):366-71.

27. Jiang H, Lu Z, Lei H, Zhao D, Yang B, Huang C. Predictors of early recurrence and delayed cure after segmental pulmonary vein isolation for paroxysmal atrial fibrillation without structural heart disease. J Interv Card Electrophysiol. 2006;15(3):157-63.

\section{Submit your next manuscript to BioMed Central and we will help you at every step:}

- We accept pre-submission inquiries

- Our selector tool helps you to find the most relevant journal

- We provide round the clock customer support

- Convenient online submission

- Thorough peer review

- Inclusion in PubMed and all major indexing services

- Maximum visibility for your research

Submit your manuscript at www.biomedcentral.com/submit 